\title{
Caracterização de massas argilosas contendo resíduo proveniente do setor petrolífero e sua utilização em cerâmica estrutural.
}

\section{(Characterization of waste of petroleum industry containing clayey masses and its application in structural ceramics)}

\author{
R. S. Santos, G. P. Souza, J. N. F. Holanda \\ LAMAV, Universidade Estadual do Norte Fluminense - UENF \\ Av. Alberto Lamego, 2000 \\ Campos dos Goytacazes, RJ, 28015-620 \\ holanda@uenf.br
}

\begin{abstract}
Resumo
A região Norte do Estado do Rio de Janeiro é responsável pela produção de cerca de 75\% do petróleo nacional (Bacia de Campos-RJ). Na etapa de extração/separação do óleo bruto é gerada considerável quantidade de resíduo oleoso, normalmente denominado borra de petróleo. O aproveitamento deste resíduo em massas argilosas é de alto interesse tecnológico, econômico e ambiental. O objetivo deste trabalho é caracterizar e avaliar o comportamento de massas argilosas contendo borra de petróleo visando sua aplicação em cerâmica estrutural. Foram estudadas massas com os seguintes percentuais de borra de petróleo: 0, 5, 10, 15 e 20\% em peso. São apresentados os resultados das análises de difração de raios X, granulometria e limites de Atterberg, bem como a determinação de propriedades físico-mecânicas em função da temperatura de queima e percentual de borra adicionada. Os resultados revelaram que a adição do resíduo altera as características físico-química-mineralógicas e propriedades da massa argilosa pura. As massas contendo borra têm uso provável em cerâmica estrutural.
\end{abstract}

Palavras-chave: borra de petróleo, caracterização, cerâmica estrutural.

\begin{abstract}
The Northern Region of Rio de Janeiro State is responsible for the production of about $75 \%$ of the Brazilian Petroleum (Campos Basin). In the crude oil extraction/separation step, a considerable amount of oil waste is originated, usually named oil sludge waste. The use of this waste as a component of clayey masses is of high interest, as much from an economic and technological as from an environmental perspective. The purpose of this work is to characterize and evaluate some properties of waste containing clayey bodies, aiming its application on structural ceramics. Masses containing 0, 5, 10, 15 and 20 wt\% waste were investigated. Results of X-ray analysis, granulometry and Atterberg limits, as well as physical-mechanical properties as a function of waste addition are presented. The results revealed that waste additions modified the physical-chemical-mineralogical characteristics and properties of the masses. The ceramic bodies containing waste are adequate for the structural ceramic field.
\end{abstract}

Keywords: characterization, oil sludge waste, structural ceramics.

\section{INTRODUÇÃO}

Nos últimos anos tem ocorrido um crescente interesse na prevenção da poluição ambiental, minimização de resíduos e desenvolvimento sustentado, sobretudo no campo dos materiais [1].

O setor petrolífero gera enormes quantidades de resíduos de diversos tipos e níveis de periculosidade $[2,3]$. O resíduo mais abundante é o material oleoso, o qual apresenta capacidade adesiva de aglomerar areia ou pó de pedra, podendo formar uma massa de resíduo final entre 10-20 vezes maior que o resíduo inicial. Principalmente devido ao elevado teor de óleo, este tipo de resíduo não pode ser simplesmente disposto em lagos ou diques, dando origem a um problema de relevância ambiental.

A Bacia de Campos, localizada na região Norte do Estado do Rio de Janeiro, é responsável por cerca de $75 \%$ do petróleo produzido no Brasil [4]. No processo de extração de óleo cru nesta Bacia são geradas cerca de 80 toneladas/mês de um 
resíduo oleoso denominado borra de petróleo. Este resíduo é proveniente da separação do óleo cru bruto de impurezas sólidas e líquidas nas plataformas marítimas de produção.

Por ser um resíduo químico tóxico classificado como classe I - perigoso [5], o mesmo não pode ser lançado diretamente no meio ambiente ou comercializado. A prática comum para destino deste resíduo tem sido o seu armazenamento em tambores. Atualmente, a borra de petróleo bruta é submetida a um tratamento com um agente encapsulante. Este tratamento consiste basicamente em misturar a borra oleosa com $20 \%$ em peso de bentonita organofílica em forma de pó. O encapsulante tem a função de formar uma barreira física permanente no resíduo, evitando a lixiviação de produtos tóxicos para o meio ambiente, sobretudo o solo e as águas superficiais. Após encapsulamento a borra é classificada como classe II - não inerte [5]. Sua disposição final como material para capeamento de aterro sanitário vem sendo testada. Entretanto, esta ainda não é uma solução definitiva do ponto de vista ambiental.

Uma alternativa interessante, ainda não posta em prática, é o aproveitamento desta borra em massas argilosas para obtenção de produtos de cerâmica estrutural de forma eco-eco (econômica-ecológica).

Neste trabalho são apresentados os resultados sobre a caracterização e propriedades físico-mecânicas de massas contendo borra de petróleo, visando determinar suas potencialidades para utilização em cerâmica estrutural. Trabalhos preliminares $[6,7]$ têm mostrado que, do ponto de vista ambiental, o emprego desta borra de petróleo encapsulada para fabricação de produtos de cerâmica estrutural não causa danos ao meio ambiente.

\section{MATERIAIS E MÉTODOS}

Os materiais utilizados no presente trabalho foram: argila vermelha e borra de petróleo encapsulada. A argila é proveniente da região de Campos dos Goytacazes-RJ normalmente utilizada

Tabela I - Composição química da argila utilizada [9]. [Table I - Chemical composition of the clay [9].]

\begin{tabular}{lc}
\hline Compostos & \% em Peso \\
\hline $\mathrm{SiO}_{2}$ & 42,73 \\
\hline $\mathrm{Al}_{2} \mathrm{O}_{3}$ & 32,40 \\
\hline $\mathrm{Fe}_{2} \mathrm{O}_{3}$ & 8,61 \\
\hline $\mathrm{TiO}_{2}$ & 1,32 \\
\hline $\mathrm{MnO}$ & 0,03 \\
\hline $\mathrm{MgO}$ & 0,77 \\
\hline $\mathrm{CaO}$ & 0,11 \\
\hline $\mathrm{K} 2 \mathrm{O}$ & 1,24 \\
\hline $\mathrm{Na} \mathrm{O}_{2}$ & 0,32 \\
\hline $\mathrm{PF}$ & 12,47 \\
\hline$P F=$ perda ao fogo & \\
\hline
\end{tabular}

pelas Cerâmicas para fabricação de tijolos. Já a borra de petróleo encapsulada é oriunda da Bacia de Campos-RJ e foi fornecida pela Petrobras.

A argila usada apresenta a caulinita como argilomineral predominante, além de pequenas quantidades de ilita/mica, quartzo e gibsita [8]. Sua composição química é dada na Tabela I [9]. A Tabela II mostra as principais características da borra de petróleo oleosa bruta [10].

As massas cerâmicas estudadas (- 60 mesh) foram preparadas com as seguintes adições de borra de petróleo encapsulada: $0,5,10,15$ e 20 em \% em peso. As massas preparadas foram caracterizadas sob os seguintes aspectos: difração de raios X (Seifert, modelo URD 65) utilizando-se radiação $\mathrm{Cu}-\mathrm{K} \alpha$, granulometria (NBR 7181-84) [11], massa específica real dos grânulos (NBR 6508-84) [12] e limites de Atterberg (NBR 6459-84 [13] e NBR 7180-84 [14]).

Os corpos de prova obtidos por prensagem uniaxial em 24 $\mathrm{MPa}$ numa matriz retangular $\left(11,50 \times 2,25 \mathrm{~cm}^{2}\right)$, foram posteriormente secos em estufa $\left(110^{\circ} \mathrm{C}\right.$ por $\left.24 \mathrm{~h}\right)$. A queima foi realizada em temperaturas de 850 até $1100{ }^{\circ} \mathrm{C} \mathrm{em} \mathrm{forno}$ tipo mufla com microprocessador, sendo os corpos de prova mantidos na temperatura final de queima por $2 \mathrm{~h}$. A taxa de aquecimento foi de aproximadamente $2{ }^{\circ} \mathrm{C} / \mathrm{min}$ com patamar em $600{ }^{\circ} \mathrm{C}$ durante $1 \mathrm{~h}$. De $600{ }^{\circ} \mathrm{C}$ até a temperatura final de patamar a taxa foi de $10{ }^{\circ} \mathrm{C} / \mathrm{min}$. O resfriamento foi realizado por convecção natural, desligando-se o forno após os corpos de prova serem mantidos na temperatura de patamar final pelo tempo determinado. As seguintes propriedades dos corpos de prova após queima foram determinadas: retração linear [15], absorção de água [16], massa específica aparente [16], porosidade aparente [16] e módulo de ruptura à flexão em carregamento de três pontos [17].

\section{RESULTADOS E DISCUSSÃO}

Tabela II - Principais características do resíduo oleoso [10]. [Table II - Main characteristics of oil waste [10].]

\begin{tabular}{|c|c|}
\hline Composição Típica & $\%$ em Peso \\
\hline Sólidos & 62,02 \\
\hline Água & 21,90 \\
\hline Hidrocarbonetos (Óleo) & 16,07 \\
\hline Enxofre & 1,46 \\
\hline \multicolumn{2}{|c|}{ Outras Características } \\
\hline \multicolumn{2}{|c|}{ Tipos de Sólidos: argila, sílica e óxidos } \\
\hline \multicolumn{2}{|c|}{ Poder calorífico: $2.078 \mathrm{kcal} / \mathrm{kg}$} \\
\hline \multicolumn{2}{|c|}{ Aspecto: líquido viscoso escuro } \\
\hline Produção estimada: $\varepsilon$ & l /mês \\
\hline
\end{tabular}

A Fig. 1 mostra os difratogramas de raios $\mathrm{X}$ para as massas argilosas contendo teores variados de borra de petróleo encapsulada. Nesta figura observa-se os picos característicos 


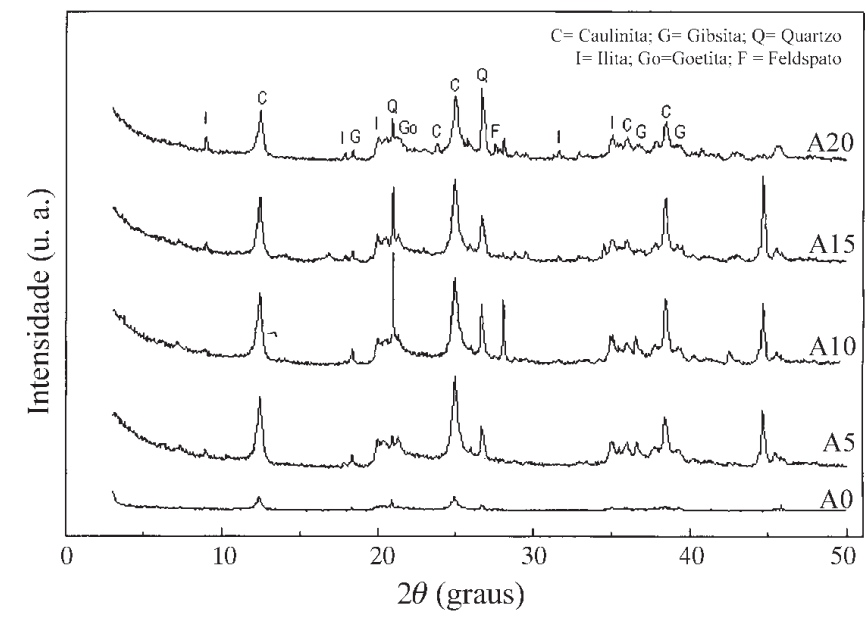

Figura 1: Difratogramas de raios $\mathrm{X}$ das massas utilizadas.

[Figure 1: X-Ray diffractograms of the ceramic masses.]

dos argilominerais e dos minerais acessórios presentes nas amostras. $\mathrm{O}$ argilomineral predominante, para todas as amostras estudadas, é a caulinita, sendo os seus picos apresentados de forma bem definida. Além da caulinita, é possível detectar picos característicos dos minerais ilita/mica, quartzo e gibsita. Nos difratogramas há indícios também da presença de sulfato de bário, feldspato potássico e goetita, sendo que a baixa intensidade dos picos torna pouco precisa a identificação dos mesmos. O sulfato de bário é proveniente da borra de petróleo encapsulada. Este material origina-se do fluido de perfuração empregado na extração de petróleo da Bacia de Campos [18].

Os dados relativos a granulometria para as massas estudadas estão resumidos na Tabela III. Os dados para a massa argilosa pura também são apresentados para efeito de comparação.

O comportamento granulométrico revela que todas as massas preparadas consistem de um material constituído de partículas na faixa de 2 até $600 \mu \mathrm{m}$. A fração argila varia de 47 a $57 \%$, seguido pelo silte de 37 a $39 \%$ e areia de 6 a 14\%. A adição de borra à massa argilosa pura provoca modificação na granulometria. O conteúdo da fração argila diminui com concomitante aumento do teor de areia, à medida que se aumenta o percentual de borra adicionada à massa argilosa. Já o conteúdo de silte permanece praticamente constante. Com a adição de borra de petróleo, a fração areia aumentou e as massas
Tabela IV - Limites de Atterberg para as massas cerâmicas. [Table IV - Atterberg limits for the ceramic masses.]

\begin{tabular}{lccc}
\hline & \multicolumn{2}{c}{ Limites de Consistência de Atterberg } \\
\hline Amostra & $\begin{array}{c}\text { Limite de } \\
\text { Liquidez } \\
(\%)\end{array}$ & $\begin{array}{c}\text { Limite de } \\
\text { plasticidade }\end{array}$ & $\begin{array}{c}\text { Índice de } \\
\text { Plasticidade } \\
(\%)\end{array}$ \\
\hline A0 & 69 & 25 & $(\%)$ \\
\hline A5 & 64 & 28 & 44 \\
\hline A10 & 62 & 27 & 36 \\
\hline A15 & 56 & 26 & 35 \\
\hline A20 & 53 & 24 & 30 \\
\hline
\end{tabular}

adquiriram maior conteúdo de partículas não argilosas, tais como quartzo e sulfato de bário. Estas partículas tendem a influenciar a plasticidade das massas, bem como leva a uma baixa retração linear [19].

A Tabela IV mostra os valores obtidos para os limites de Atterberg das massas estudadas, os quais são considerados apropriados para moldagem por extrusão [20]. Pode-se observar que à medida que se adiciona borra à massa argilosa pura, ocorre diminuição dos limites de consistência de Atterberg. Estes dados corroboram aqueles da granulometria das massas, onde o aumento do percentual de quartzo e sulfato de bário, os quais são materiais não plásticos, contribuem para diminuição da plasticidade das massas argilosas. Ainda, estas massas podem ser classificadas do ponto de vista de mecânica dos solos, como pertencentes ao grupo de argilas inorgânicas de alta plasticidade [21].

De modo geral, as propriedades físico-mecânicas são influenciadas, tanto pela borra quanto pela temperatura de queima. Contudo, o efeito da temperatura de queima é mais pronunciado.

A contração linear dos corpos de prova em função do percentual de borra e da temperatura de queima é mostrado na Fig. 2. Os valores de retração linear, na faixa de 1,47 até $6,02 \%$ para os corpos de prova contendo borra, mostraram-se satisfatórios para as temperaturas empregadas. Os resultados

Tabela III - Distribuição de tamanho de partículas das massas cerâmicas preparadas com adição de borra de petróleo encapsulada. [Table III - Particle size distribution of the ceramic masses prepared by adding oil waste.]

\begin{tabular}{|c|c|c|c|c|c|c|c|}
\hline \multirow[b]{2}{*}{ Amostra } & \multirow[b]{2}{*}{ Argila $^{1}$} & \multicolumn{3}{|c|}{ Silte $(\%)$} & \multicolumn{2}{|c|}{ Areia $(\%)$} & \multirow{2}{*}{$\begin{array}{c}\text { Massa Específica } \\
\text { Real dos Grãos }\left(\mathrm{g} / \mathrm{cm}^{3}\right)\end{array}$} \\
\hline & & Fino $^{2}$ & Médio ${ }^{3}$ & Grosso $^{4}$ & Fina $^{5}$ & Média $^{6}$ & \\
\hline A0 & 57 & 13,4 & 16,0 & 7,0 & 4,8 & 1,8 & 2,55 \\
\hline A5 & 56 & 13,8 & 15,0 & 8,4 & 4,8 & 2,0 & 2,66 \\
\hline A10 & 54 & 13,9 & 15,9 & 8,7 & 5,1 & 2,4 & 2,63 \\
\hline A15 & 50 & 13,0 & 14,5 & 11,0 & 8,2 & 3,3 & 2,62 \\
\hline A20 & 47 & 13,2 & 14,7 & 11.2 & 9,2 & 4,7 & 2,59 \\
\hline
\end{tabular}




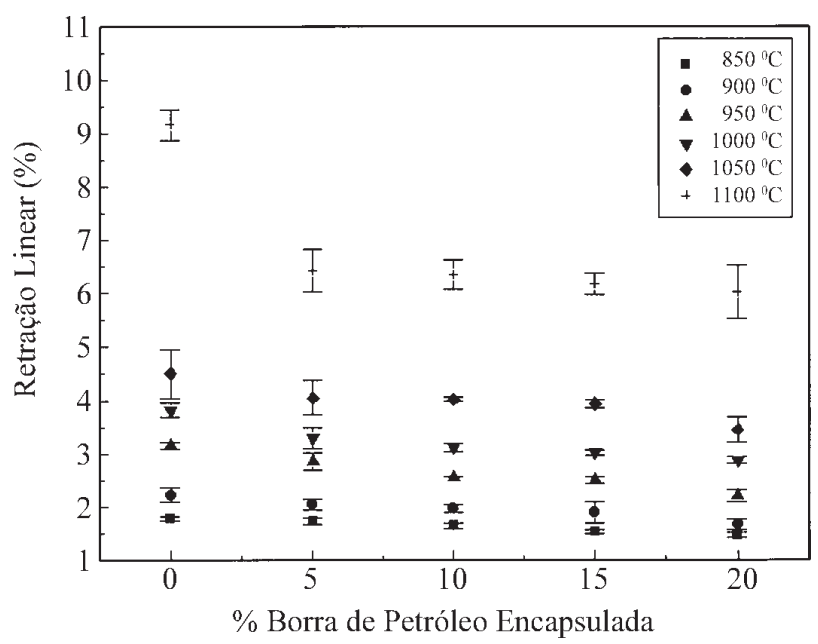

Figura 2: Retração linear dos corpos de prova em função do percentual de borra de petróleo encapsulada e da temperatura de queima.

[Figure 2: Linear shrinkage as a function of waste percentage for all firing temperatures.]

mostram que o aumento do conteúdo de borra tende a diminuir a retração linear dos corpos de prova. A razão para isto pode estar relacionada ao quartzo e sulfato de bário presentes na borra, que são materiais não plásticos e diminuem o conteúdo de argila na massa, contribuindo para a diminuição da retração linear. Observa-se que para adição de $5 \%$ de borra à massa argilosa, ocorre diminuição da retração linear. A partir de então, a adição de borra praticamente não altera os valores de retração linear. Ao contrário, a temperatura de queima afeta significativamente a retração linear dos corpos de prova. Quanto maior for a temperatura de queima, maior é a retração dos corpos de prova. Acima de $1000{ }^{\circ} \mathrm{C}$, com o maior grau de vitrificação a retração de queima é mais acentuada.

A Fig. 3 mostra o comportamento da absorção de água em função do percentual de borra encapsulada e da temperatura de queima. É observado que as massas não apresentam

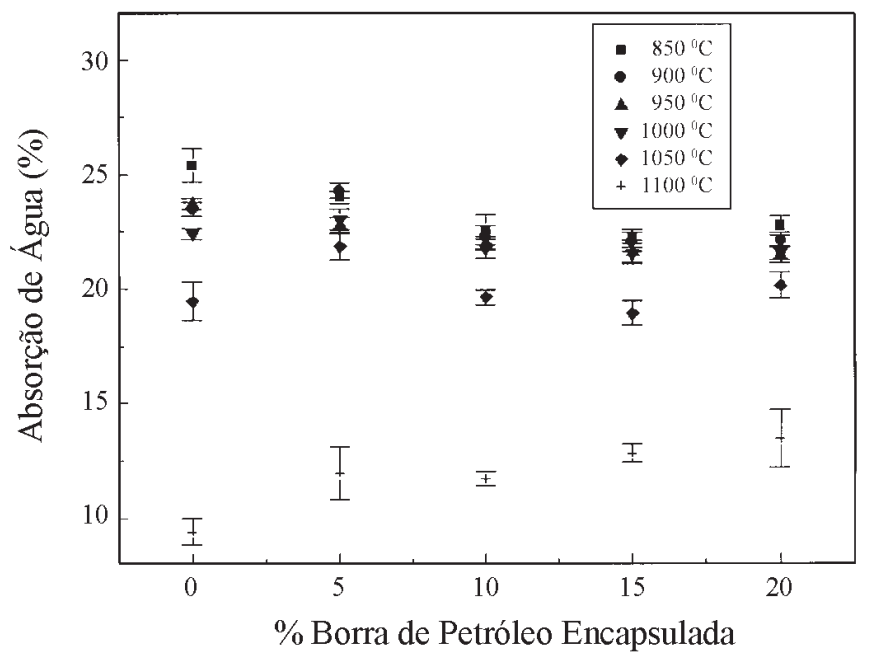

Figura 3: Absorção de água dos corpos de prova em função do percentual de borra de petróleo encapsulada e da temperatura de queima.

[Figure 3: Water absorption as a function of waste percentage for all firing temperatures.] variações significativas nos valores de absorção de água até a temperatura de $1000{ }^{\circ} \mathrm{C}$. Já acima de $1000{ }^{\circ} \mathrm{C}$ ocorre grande redução nos valores de AA e, portanto, da porosidade aberta dos corpos de prova. Tal comportamento está relacionado a formação de uma maior quantidade de fase líquida, com provável predominância de sinterização por fluxo viscoso [20]. Em geral ocorre um aumento de AA entre 0 e $5 \%$ de borra adicionada, revelado pelo maior pico de AA. Um novo aumento de borra na massa, provoca a diminuição da AA, sendo $10 \%$ o seu valor limite. A partir daí, a absorção de água praticamente não é alterada pela adição de borra. Os dados de porosidade aparente (Fig. 4) e massa específica aparente (Fig. 5) dos corpos de prova seguem o mesmo comportamento observado para a absorção de água.

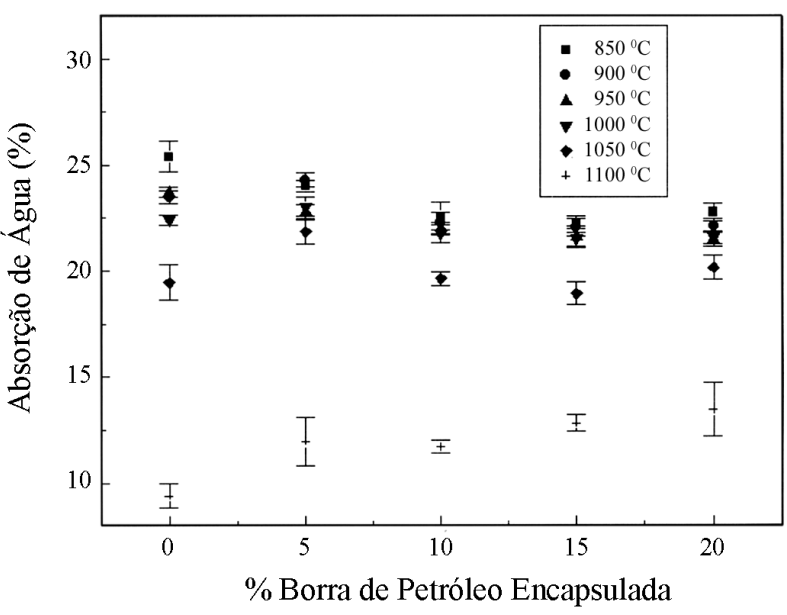

Figura 4: Porosidade aparente dos corpos de prova em função do percentual de borra de petróleo encapsulada e da temperatura de queima.

[Figure 4: Apparent porosity as a function of waste percentage for all firing temperatures.]

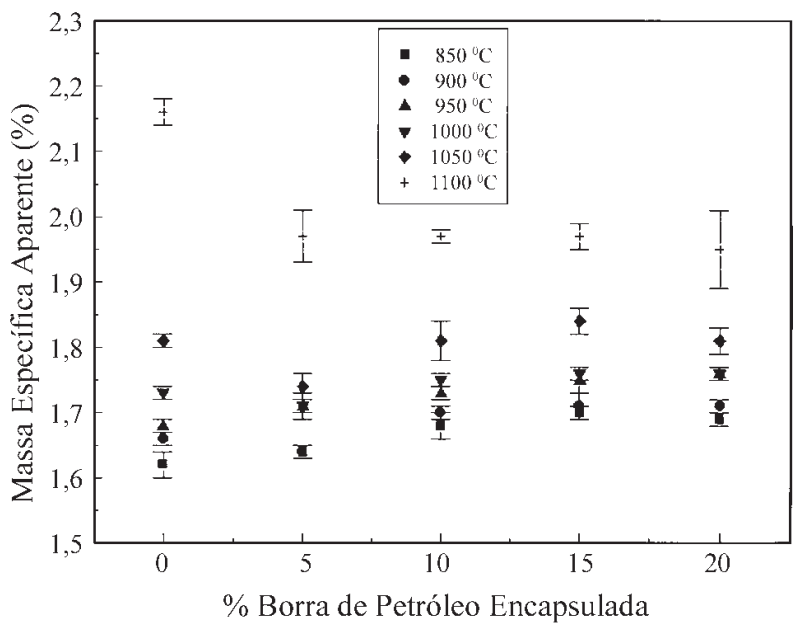

Figura 5: Massa específica aparente dos corpos de prova em função do percentual de borra de petróleo encapsulada e da temperatura de queima.

[Figure 5: Apparent density as a function of waste percentage for all firing temperatures.] 


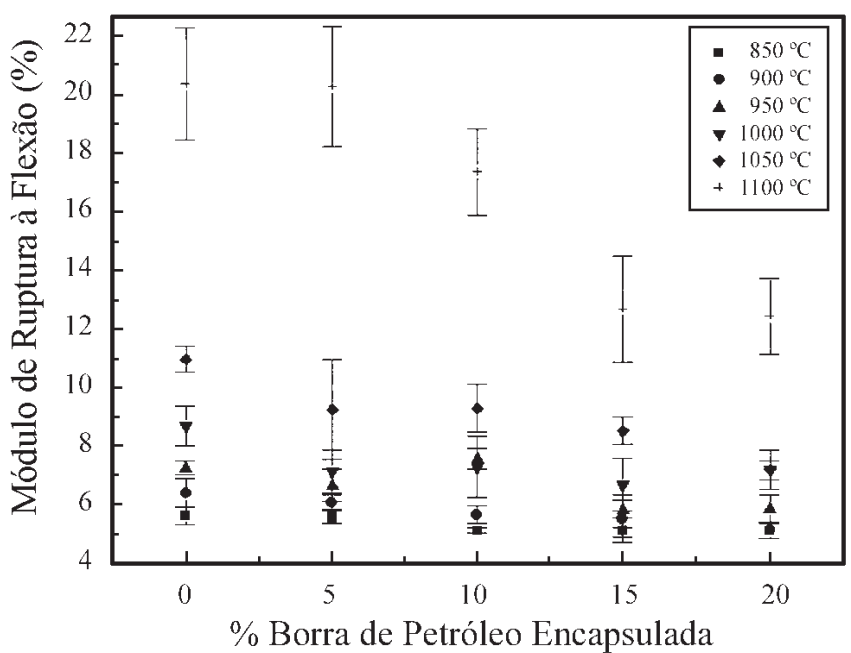

Figura 6: Módulo de ruptura à flexão dos corpos de prova em função do percentual de borra de petróleo encapsulada e da temperatura de queima.

[Figure 6: Flexure strength modulus as a function of waste percentage for all firing temperatures.]

O valor especificado de absorção de água para tijolos maciços e blocos cerâmicos $(<25 \%)$ [22] é atingido já a partir de $850^{\circ} \mathrm{C}$. Já para telhas que exigem valores inferiores a $20 \%$, ele só é alcançado em temperaturas a partir de $1050{ }^{\circ} \mathrm{C}$. Para aplicação em cerâmica de revestimento, os corpos de prova atingiram os valores especificados para revestimento poroso $(10 \%<\mathrm{AA}<$ $20 \%$ ) [23] somente quando queimados a $1100^{\circ} \mathrm{C}$.

Os dados de módulo de ruptura à flexão (Fig. 6) corroboram os resultados discutidos anteriormente. De maneira geral o módulo de ruptura aumenta com o aumento da temperatura de queima, sendo que acima de $1000{ }^{\circ} \mathrm{C}$ o aumento é mais acentuado. Ao contrário, verifica-se que a borra provoca uma queda suave no módulo de ruptura dos corpos de prova. Isto é decorrente da modificação das características químicamineralógica-física da massa argilosa pura, provocada pela adição da borra que interfere no processo de sinterização.

Os resultados também mostram que as massas estudadas já a partir de $850^{\circ} \mathrm{C}$ atingem os valores especificados para fabricação de tijolos maciços e blocos cerâmicos, que são de 2,0 MPa e 5,5 $\mathrm{MPa}$, respectivamente. A especificação para telhas de 6,5 $\mathrm{MPa}$ é atingida à partir de $950{ }^{\circ} \mathrm{C}$, para todas as massas estudadas. Para fabricação de revestimento poroso de parede com espessura inferior a 7,5 mm, o qual exige resistência mecânica mínima de $12 \mathrm{MPa}$, somente os corpos de prova das massas A10 e A15 atingiram o valor quando queimados a $1100^{\circ} \mathrm{C}$.

A cor após queima é também um critério importante usado para classificação de uma massa argilosa para fins cerâmicos. Todos os corpos de prova obtidos no presente trabalho apresentaram cor vermelha (2,5 YR/6 no dicionário Munsell de cores), independente do conteúdo de borra encapsulada adicionada e temperatura de queima utilizada.

\section{CONCLUSÕES}

As seguintes conclusões podem ser tiradas dos resultados obtidos neste trabalho: a) As massas contendo borra, do ponto de vista mineralógico, são constituídas pelos argilominerais caulinita e ilita/mica, com predominância de caulinita, bem como dos minerais acessórios quartzo e gibsita. Há indícios da presença de feldspato potássico, sulfato de bário e goetita.

b) As características das massas são alteradas em função da adição da borra encapsulada, que introduz areia na massa argilosa pura. Com isso, ocorre aumento do teor de quartzo e diminuição da fração argila $(<2 \mu \mathrm{m})$, bem como diminuição da plasticidade das massas.

c) As propriedades físico-mecânicas são afetadas tanto pela borra de petróleo adicionada quanto pela temperatura de queima. Sendo que o efeito da temperatura é mais acentuado, principalmente acima de $1000{ }^{\circ} \mathrm{C}$. A cor de queima vermelha das massas contendo borra é apropriada para produtos de cerâmica estrutural.

d) Os resultados mostram que a borra apresenta potencial para ser utilizada como constituinte de massas argilosas para fabricação de produtos de cerâmica estrutural.

\section{AGRADECIMENTOS}

Os autores deste trabalho gostariam de agradecer às Instituições FENORTE-UENF, CAPES e FAPERJ (Processo E-26/171.474/99) pelo apoio financeiro.

\section{REFERÊNCIAS}

[1] J. Szekely, G. Trapaga, J. Mater. Res. 10, 9 (1995) 21782196.

[2] S. P. Amaral, G. H. Domingues, Anais do $4^{\circ}$ Congresso Brasileiro de Petróleo, Rio de Janeiro-RJ, (1990) 1-13.

[3] L. M. Curran, J. of Hazardous Mater. 29 (1992) 189-197.

[4] Petrobras - Petrobras News: http://www.petrobras.com/ ingles/revista/not11.htm (2000).

[5] Petrobras, Tratamento de Borra Oleosa, Relatório Interno, Rio de Janeiro-RJ (1998).

[6] F. A. N. Silva, Dissertação de Mestrado, Universidade Estadual do Norte Fluminense, CCT-LAMAV, Campos dos Goytacazes-RJ (2000) 134-141.

[7] R. S. Santos, Dissertação de Mestrado, Universidade Estadual do Norte Fluminense, CCT-LAMAV, Campos dos Goytacazes-RJ (2001) 89-90.

[8] J. N. F. Holanda, G. P. Souza, Anais do $43^{\circ}$ Congresso Brasileiro de Cerâmica, Florianópolis-SC, Junho (1999) 82018210.

[9] G. P. Souza, Monografia de Fim de Curso, Universidade Estadual do Norte Fluminense, CCT-LAMAV, Campos dos Goytacazes-RJ (1999) 42.

[10] E. A. Carvalho, E. M. S. Oliveira, R. S. Santos e S. N. Monteiro, Anais do 53 Congresso de Tecnologia Metalúrgica e de Materiais, ABM, Belo Horizonte - MG, Setembro (1998) 1168 .

[11] ABNT, NBR 7181-84, Solo: Análise Granulométrica, (1984).

[12] ABNT, NBR 6508 - 84, Solo: Massa Específica Real dos Grânulos, (1984).

[13] ABNT, NBR 6453 - 84, Solo: Determinação do Limite de 
Liquidez, (1984).

[14] ABNT, NBR 7180 - 84, Solo: determinação do Limite de Plasticidade, (1984).

[15] ABNT, NBR MB 305, Determinação da Retração Linear, (1984).

[16] ASTM, C 378 - 88, Test Method for Water Absorption, Bulk Density, Apparent Porosity and Apparent Specific Gravity of Fired Whiteware Products, (1988).

[17] ASTM, C 674 - 77, Flexural Properties of Ceramic Whiteware Materials, (1977).

[18] G. P. Souza, Dissertação de Mestrado, Universidade
Estadual do Norte Fluminense, CCT-LAMAV, Campos dos Goytacazes-RJ (2001) 64.

[19] P. S. Santos, Ciência e Tecnologia de Argilas, $2^{\text {a }}$ edição, Vol. 1, Editora Edgard Blücher Ltda, São Paulo, Brasil (1989) 215.

[20] C. M. F. Vieira, J. N. F. Holanda, D. G. Pinatti, Cerâmica 46, 297 (2000) 15-18.

[21] L. F. A. Campos, R. S. Macedo, P. K. Kiyohara e H. C. Ferreira, Cerâmica 45, 295 (1999) 144-145.

[22] Polo Produções, Anuário Brasileiro de Cerâmica Vermelha, editor: J. L. Francisco, Criciúma - SC (2000) 36-38.

[23] C.T.C. P. Ferreira, Cerâmica Industrial 5, 2 (2000) 10-11. (Rec. 15/03/01, Rev. 16/11/01, Ac. 14/12/01) 